\title{
The effectiveness of non-pharmacological healthcare interventions for asthma management during pregnancy: a systematic review
}

\author{
Elida Zairina ${ }^{1}$, Kay Stewart ${ }^{1}$, Michael J Abramson ${ }^{2,3}$ and Johnson George ${ }^{1 *}$
}

\begin{abstract}
Background: While reviews have been published on asthma management in pregnant women, none has examined the effectiveness of non-pharmacological healthcare interventions for optimizing asthma management in pregnant women. This systematic review aims to identify non-pharmacological healthcare interventions for optimizing asthma management during pregnancy and to examine their effects on maternal asthma control and neonatal outcomes.

Methods: The Cochrane Central Register of Controlled Trials (CENTRAL, Cochrane Library), MEDLINE, EMBASE, PsycINFO, CINAHL Plus and International Pharmaceutical Abstracts (IPA) were searched. Two reviewers independently assessed the identified studies against the eligibility criteria and extracted relevant information. The effects of the intervention were assessed qualitatively.

Results: Nine studies were identified, of which six were rejected according to the exclusion criteria. The three studies included in the final review described an education program, progressive muscle relaxation (PMR) and Fraction of exhaled Nitric Oxide (FeNO) guided management of asthma in pregnant women. The PMR and FeNO-guided interventions showed significant improvements in maternal asthma control (lung function and quality of life) and neonatal outcomes (birth weight).

Conclusions: Further evidence from well-designed studies evaluating non-pharmacological healthcare interventions for optimizing asthma management in pregnant women is required.
\end{abstract}

Keywords: Asthma, Non-pharmacological, Interventions, Management, Pregnancy

\section{Background}

Asthma is one of the most serious health problems affecting people of all ages throughout the world $[1,2]$. In the United States of America the prevalence of self-reported asthma among pregnant women was between $8.4 \%$ and $8.8 \%$ during the period 1997 to 2001 , and $4.1 \%$ of all pregnant women had experienced an asthma attack in the previous year [3,4]. In Australia, asthma is the most common chronic disease affecting pregnant women, complicating one in eight pregnancies [5].

\footnotetext{
* Correspondence: Johnson.George@monash.edu

${ }^{1}$ Centre for Medicine Use and Safety, Monash University, Parkville, VIC, Australia

Full list of author information is available at the end of the article
}

A prospective study conducted by Schatz et al. [6] of 366 pregnancies in 330 women with asthma, showed that during pregnancy, asthma improved in slightly more than a quarter of patients (28\%), worsened in slightly more than a third of patients (35\%) and remained unchanged in a third of patients (33\%). More than half of women with asthma do not take their asthma preventer medications on a regular basis before and during pregnancy, leading to asthma exacerbations [3,7]. Good asthma control during pregnancy is important to reduce risks for both mother (e. g. pre-eclampsia, perinatal mortality, and need for cesarean delivery) and infant (e.g. low birth weight and prematurity) $[8,9]$. Therefore, pregnant women with asthma warrant additional support comprising education, ongoing monitoring and review of treatment [10]. 
Many national and international bodies have developed guidelines for asthma management in pregnancy. They include the British Thoracic Society, National Heart Lung and Blood Institute (NHLBI), American College of Obstetricians \& Gynecologists (ACOG) and the American College of Asthma and Allergy (ACAAI), National Asthma Council of Australia (NAC), and Global Initiative for Asthma (GINA) [11-15]. All these guidelines have emphasized the need to provide optimal therapy to maintain control of asthma throughout gestation for maternal health and quality of life as well as for normal fetal maturation. The Expert Panel Report of the Working Group on Asthma and Pregnancy - Updates in National Asthma Education and Prevention Program (NAEPP) has recommended four critical components for managing asthma during pregnancy: (1) assessment and monitoring of asthma including objective measures of pulmonary function, (2) control of factors contributing to asthma severity, (3) patient education, and (4) a stepwise approach to pharmacological therapy [16]. Asthma management during pregnancy requires close collaboration among obstetricians, primary care physicians, and asthma-care specialists [17]. Better asthma control can be achieved if patients are involved in self-management, including selfmonitoring of either symptoms or peak expiratory flow rates, maintaining regular contact with medical practitioners and following written asthma action plans [18].

While there are many published reviews of pharmacological asthma management in pregnant women $[19,20]$, none has assessed the effectiveness of non-pharmacological healthcare interventions for optimizing asthma management in pregnant women. Most of the interventions in pregnant women have focused on the safety and efficacy of asthma medications in pregnant women [21,22]. General practitioners (family physicians) have reported a lack of confidence and/or knowledge in managing deteriorating asthma in pregnancy, although having a good understanding of the safety of asthma medications during pregnancy [23]. Despite being concerned about health outcomes, women are not well supported in managing asthma during pregnancy [24]. Empirical evidence on interventions to optimize asthma management during pregnancy, targeting both pregnant women with asthma and their health professionals, is needed. The aim of this review was to identify non-pharmacological healthcare interventions for optimizing asthma management during pregnancy and examine their effects on maternal asthma symptoms and neonatal outcomes.

\section{Methods}

\section{Eligibility criteria}

To be included, studies had to describe the effectiveness of non-pharmacological healthcare interventions for managing asthma in pregnant women using one of the following prospective study designs: randomized controlled trials (RCTs) controlled clinical trials (CCTs), or pre- and post(uncontrolled before and after) studies. Studies of nonpharmacological healthcare interventions in pregnant women, including behavioral or educational interventions targeting patients, patient self-management programs, patient monitoring and follow-up of asthma management were eligible. Studies were excluded if they were not aimed at pregnant women with asthma, comprised only pharmacological interventions in the absence of intervention by a healthcare professional (e. g. drug trials), or only targeted healthcare professionals (e. g. education to improve prescribing). Studies needed to have measured at least one of the following primary or secondary outcomes at baseline and at follow-up:

\section{Primary outcomes for the review}

1. Asthma symptom scores measured using any validated instrument (e.g. Juniper's Asthma Control Questionnaire [ACQ] [25]).

2. Health-related Quality of Life (HRQoL) scores measured using any validated instrument (e.g. Asthma Quality of Life Questionnaire-Marks [AQLQ-M] [26]).

3. Asthma -related scheduled or unscheduled healthcare visits to emergency department (ED), general practitioner (GP), or hospitalization.

\section{Secondary outcomes}

1. Lung function measurements (e.g. Peak expiratory flow rate $[\mathrm{PEFR}]$, Forced expiratory volume in one second $\left[\mathrm{FEV}_{1}\right]$, Forced vital capacity [FVC]).

2. Asthma medication adherence (assessed using a valid instrument or objective data).

3. Neonatal outcomes (e.g. birth weight, survival, Appearance, Pulse, Grimace, Activity, Respiration (APGAR) scores, gestational age).

\section{Information sources}

A systematic search of the following databases was carried out using the Cochrane Central Register of Controlled Trials (CENTRAL, The Cochrane Library 2013), Ovid MEDLINE, Ovid EMBASE, Ovid PsycINFO, CINAHL Plus and International Pharmaceutical Abstracts (IPA). In addition to searching these databases, reference lists from previously published review articles were also searched. The final search was carried out in October 2013.

\section{Search strategies}

Professional librarians were consulted in developing the search strategy for each database. No language restrictions 
were used and searches were not limited to publication years. The broad terms asthma* AND pregnan* as (text word) were used. The following keywords were entered: asthma* OR wheez* OR, bronchoconstrict* OR bronchospas* AND pregnancy* OR pregnant OR maternal* in combination with clinical trials OR randomized controlled trials OR controlled clinical trials. Additional searches using the Medical Subject Headings (MeSH) 'asthma' and 'pregnancy' were performed in Medline and PubMed.

\section{Study selection}

One author (EZ) ran the search strategy described above. All studies identified were imported into an Endnote ${ }^{\circ}$ library (version X6, Thomson Reuters). After removal of duplicates, the remaining titles and abstracts were reviewed by EZ to exclude studies that did not meet the inclusion criteria. Full texts of all studies that were considered relevant on the basis of review of title and abstract were retrieved, read and assessed independently by two reviewers (EZ and JG).

\section{Data collection process and data items}

Using an electronic data extraction form [27], one author (EZ) extracted the data from included studies, which were verified by a second author (JG). Any disagreements and uncertainties were identified and resolved in discussion with an adjudicating third author (KS). Given the clinical heterogeneity of the studies included, a qualitative assessment of the effects of the intervention was performed, based on the methodological quality and the study outcomes. The effects of the intervention were described by comparing the difference in outcome measures from baseline to end of the study between the groups. If more than one outcome was reported, priority was given to validated measures [28].

\section{Results}

\section{Study selection}

Figure 1 shows the process of selection of studies for the systematic review, based on PRISMA guidelines [29]. Overall, 2,387 references published until 9 October 2013 were identified in the preliminary search: Ovid MEDLINE $(\mathrm{n}=636)$, Ovid EMBASE $(\mathrm{n}=779)$, CINAHL Plus $(\mathrm{n}=337)$, Ovid PsycINFO $(\mathrm{n}=22)$, IPA $(\mathrm{n}=137)$, Ovid CENTRAL $(n=143)$ and PubMed $(n=333)$. Screening of the reference lists of published articles resulted in identification of another 18 articles. After combining the results from each database and removal of duplicate titles from Endnote ${ }^{\oplus}$, 1,717 unique studies remained. After further screening, 1,461 were removed due to irrelevant titles or abstracts, leaving 256 studies for further scrutiny; 247 studies were excluded after further review. Of the nine full-text articles obtained, one was a narrative review [30], one had a retrospective design [31], one had a cross-sectional design [32] and three were based on secondary analysis of other studies [33-35] leaving only three original studies for the final review [36-38].

\section{Study characteristics}

The characteristics and results of the three studies included in the final review are summarized in Table 1. These studies evaluated the following interventions in pregnant women: an education program [36], progressive muscle relaxation (PMR) [37] and management of asthma guided by Fraction of exhaled Nitric Oxide (FeNO) [38]. Heterogeneity in study design, setting, type of intervention, follow-up and outcome measures were found among the three studies. Two studies took place in the antenatal clinic of one Australian hospital [36,38] and another [37] in Germany. All three interventions were conducted in clinics or hospital settings.

\section{Methodological quality}

All three studies had methodological limitations. The education program in the uncontrolled pre- and posttest design study was delivered by the same personnel who were involved in outcome assessment and were not masked (blinded), thus observation/detection bias might have occurred [36]. Only one of the RCTs reported allocation concealment [38]. The outcomes of both trials [37,38] were assessed by masked investigators but only one reported masking of both the participants and personnel who were involved in the intervention [38]. Sample size calculation was described for both RCTs, but not in the pre- and post-test study [36]. Participation and attrition rates varied across the three studies. Only Powell et al. [38] gave reasons for participant withdrawal (11 from the trial group and 6 from the control group). None of the study protocols were published. One trial was registered with the Australian and New Zealand Clinical Trial registry [38].

\section{Results of individual studies Education program}

Murphy et al. [36] conducted a study to implement asthma self-management skills through an education program in pregnant women with asthma in an antenatal clinic. The asthma self-management skills assessed were: medication adherence (inhaled corticosteroid [ICS] users only), knowledge about how the reliever and preventer medications worked and inhaler technique, possession of a written action plan, and self-monitoring. The medication adherence and knowledge were assessed by direct questioning, while the inhaler technique was demonstrated by the patient.

The study found that maternal and neonatal outcomes may be improved by asthma self-management education, which can be delivered in an antenatal clinic by a nurse with specific training in asthma education. Improvements 


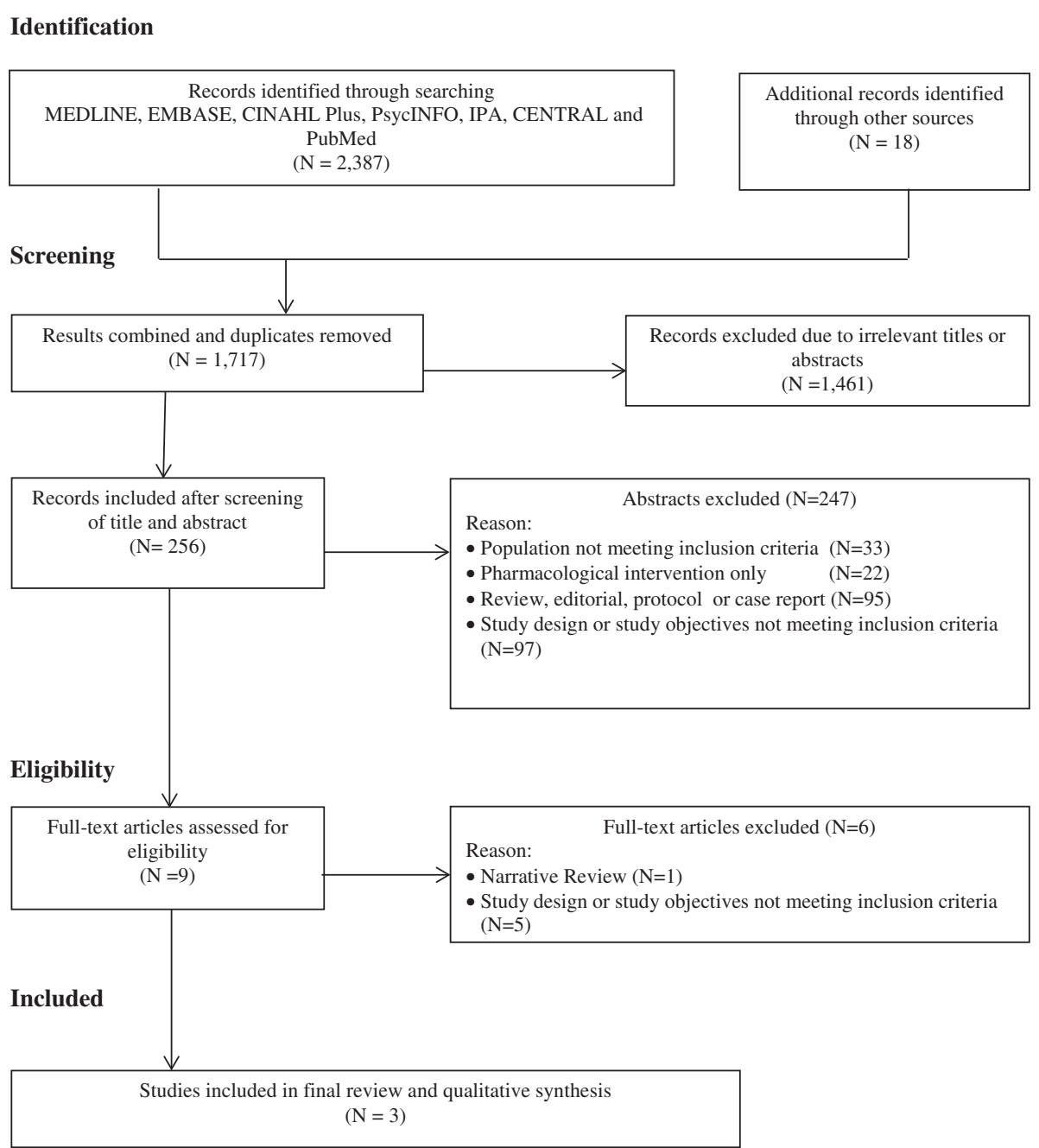

Figure 1 Flow chart of selection process for including studies in the systematic review.

in asthma medication adherence, knowledge and skills were associated with asthma education and should be considered as an important aspect of managing asthma in pregnant women [36]. There were some limitations of this study. The time elapsed ( 3 months) between the two visits was identified by the authors as a potential confounder, as changes in asthma control could be influenced by gestation and seasonal changes [36]. Since there was no comparison group, it remained unclear if the asthma management skills improved because of the asthma education provided in the antenatal clinic, as a result of other factors, or spontaneously [36].

\section{Progressive Muscle Relaxation (PMR)}

This trial by Nickel et al. [37] examined the efficacy of progressive muscle relaxation (PMR) on changes in heart rate, systolic blood pressure (SBP), lung function and quality of life in pregnant women with asthma. The PMR procedures in this study required the participants to monitor and control their state of muscular tension. In the first step, the women deliberately applied tension to certain muscle groups and then released the tension and focused on how the muscle relaxed during the process [37]. This study claimed that the PMR intervention was inexpensive and demonstrated a potential benefit in pregnant women with asthma [37]. Inability to confirm that all the participants followed the instructions was a limitation acknowledged by the authors [37]. The short term follow-up of the study (8 weeks) may have contributed to the low drop-out rate [37]. Only immediate effects were measured after an active intervention. Hence it is unknown if PMR intervention would have had similar effects in the longer term and during asthma exacerbations [37].

\section{FeNO-based algorithm}

Powell et al. [38] carried out a double-blind parallel group RCT to test whether asthma control in pregnancy would 
Table 1 Key features of studies included in the final review

\begin{tabular}{|c|c|c|c|c|c|c|c|c|}
\hline $\begin{array}{l}\text { First Author, Year, } \\
\text { study }\end{array}$ & Aim & $\begin{array}{l}\text { Setting; } \\
\text { country }\end{array}$ & Population & $\begin{array}{l}\text { Study } \\
\text { design }\end{array}$ & Interventions & Follow-up & Outcomes & Results \\
\hline $\begin{array}{l}\text { Murphy, } 2005 \text { [36] } \\
\text { "Education program" }\end{array}$ & $\begin{array}{l}\text { To determine the } \\
\text { level of asthma } \\
\text { self-management } \\
\text { skills and } \\
\text { knowledge, and } \\
\text { to implement an } \\
\text { asthma } \\
\text { education } \\
\text { program }\end{array}$ & $\begin{array}{l}\text { Antenatal clinics; } \\
\text { NSW, Australia }\end{array}$ & $\begin{array}{l}\text { Pregnant women with } \\
\text { a doctor's diagnosis } \\
\text { of asthma (mild, } \\
\text { moderate, severe) } \\
\text { at } \sim 20 \text { weeks gestation }\end{array}$ & $\begin{array}{l}\text { Pre-and } \\
\text { post- }\end{array}$ & $\begin{array}{l}\text { I: Received education } \\
\text { about asthma control and } \\
\text { self-management skills } \\
\text { from a nurse (asthma } \\
\text { educator) in two visits } \\
\text { each consisting of a } \\
30-60 \text { min session }(n=211) \\
\text { C: no control group }\end{array}$ & $\begin{array}{l}\sim 33 \text { week s } \\
\text { of gestation } \\
\text { (last visit) }\end{array}$ & $\begin{array}{l}\text { Self-reported } \\
\text { nonadherence to ICS, } \\
\text { lung function (FEV }{ }_{1} \\
\left.\mathrm{FEV}_{1} \%, \text { FVC, } F E V_{1} / F V C\right), \\
\text { symptoms and reliever } \\
\text { medication use. }\end{array}$ & 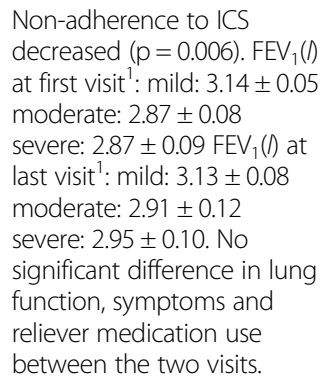 \\
\hline $\begin{array}{l}\text { Nickel, } 2006 \text { [37] } \\
\text { "Progressive Muscle } \\
\text { Relaxation (PMR)" }\end{array}$ & $\begin{array}{l}\text { To examine the } \\
\text { efficacy of PMR } \\
\text { in pregnant } \\
\text { women }\end{array}$ & $\begin{array}{l}\text { Psychosomatic } \\
\text { clinics; Germany, } \\
\text { Austria }\end{array}$ & $\begin{array}{l}\text { Pregnant women with } \\
\text { asthma who were } \\
\text { regularly seen by an } \\
\text { obstetrician/ } \\
\text { gynecologist }\end{array}$ & RCT & $\begin{array}{l}\text { I: } 30 \text { min PMR session, } \\
3 \text { times a week }(n=32) \\
\text { C: placebo }(30 \text { min sham } \\
\text { training), } 3 \text { times a week } \\
(n=32)\end{array}$ & $\begin{array}{l}8 \text { weeks } \\
\text { from } \\
\text { baseline }\end{array}$ & $\begin{array}{l}\text { Lung function (PEF, } \\
\text { FEV }_{1} \text { ), QoL (SF-36) }\end{array}$ & $\begin{array}{l}\mathrm{FEV}_{1}\left(() \text { : initial }{ }^{2}: \text { I: } 1.69 \pm 0.6\right. \\
C: 1.75 \pm 0.5 \text { final }\left.\right|^{2}: \text { I: } 2.22 \pm \\
0.5 \mathrm{C}: 1.75 \pm 0.5 \text { Difference } \\
\text { in } \mathrm{FEV}_{1}[95 \% \mathrm{Cl}]=0.5(0.2 \text { to } \\
0.8) \mathrm{p}=0.005 \text { Difference in } \\
\text { SF-36 (mental health } \\
\text { component)[95\%Cl] }=5.8 \\
\text { (1.4 to 10.2) } p=0.01\end{array}$ \\
\hline $\begin{array}{l}\text { Powell, } 2011 \text { [38] } \\
\text { "FeNO based } \\
\text { Algorithm" }\end{array}$ & $\begin{array}{l}\text { To test the } \\
\text { hypothesis that a } \\
\text { management } \\
\text { algorithm for } \\
\text { asthma in } \\
\text { pregnancy based } \\
\text { on FeNO and } \\
\text { symptoms would } \\
\text { reduce asthma } \\
\text { exacerbations }\end{array}$ & $\begin{array}{l}\text { Antenatal clinics; } \\
\text { NSW, Australia }\end{array}$ & $\begin{array}{l}\text { Non-smoking pregnant } \\
\text { women (aged } \geq 18 \text { years) } \\
\text { with asthma, } 12-20 \\
\text { weeks gestation and } \\
\text { using asthma } \\
\text { medications (e.g. } \\
\text { inhaled therapy, } \\
\text { beta } \text { - }_{2} \text {-agonist) within } \\
\text { the past year }\end{array}$ & $\begin{array}{l}\text { Double-blind } \\
\text { RCT }\end{array}$ & $\begin{array}{l}\text { I: FeNO algorithm to adjust } \\
\text { therapy: (1) FeNO } \\
\text { concentration was used to } \\
\text { adjust the dose of inhaled } \\
\text { corticosteroids (2) ACQ } \\
\text { score was used to adjust } \\
\text { the dose of long acting } \\
\text { beta }{ }_{2} \text {-agonist }(n=111) \text { C: } \\
\text { ACQ- based clinical } \\
\text { algorithm ( } n=109 \text { ) }\end{array}$ & $\begin{array}{l}\text { monthly } \\
\text { until } \\
\text { delivery }\end{array}$ & $\begin{array}{l}\text { Exacerbation types } \\
\text { (unscheduled doctor } \\
\text { visits, OCS use, hospital } \\
\text { admission, ER/labor } \\
\text { ward visits), QoL (SF-12 } \\
\text { and AQLQ-M), Lung } \\
\text { function (FEV } 1 \text { and } \\
\text { FEV } \text { F }_{1} \% \text { ), current } \\
\text { treatment and perinatal } \\
\text { outcomes }\end{array}$ & 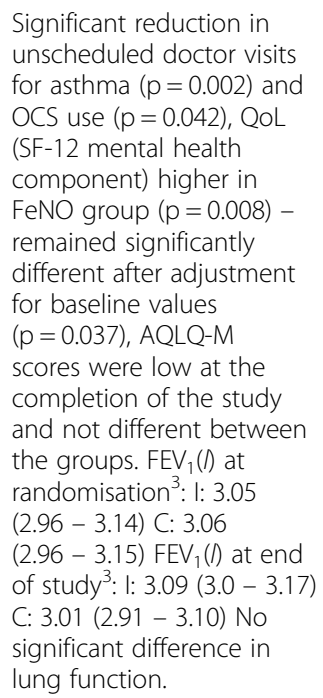 \\
\hline
\end{tabular}

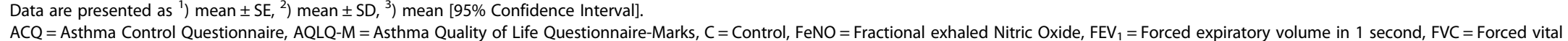
capacity, ICS = Inhaled corticosteroid,$I=$ intervention, $\mathrm{min}=$ minute, $I=$ liter, OCS = Oral corticosteroid, PEF = Peak expiratory flow rate, QoL= Quality of Life, RCT = Randomized Controlled Trial, SF-36 = Short Form 36, SF-12 = Short Form 12 
be better using a FeNO-based treatment algorithm compared to an ACQ clinical algorithm in terms of reducing asthma exacerbations. FeNO helps to identify eosinophilic airway inflammation and to adjust the dose of ICS. The FeNO-based algorithm group had a sequential process: (1) FeNO concentration to adjust the dose of ICS; and (2) ACQ score to adjust the dose of long acting beta bagonist. $_{2}$-a The clinical algorithm was based on asthma control assessed with Juniper's ACQ questionnaire. The data collected included clinical symptoms, ACQ, quality of life questionnaires (AQLQ-M and SF-12), present treatment (ICS and $\beta_{2}$ agonist), FeNO and spirometry $\left(\mathrm{FEV}_{1}, \mathrm{FVC}\right)$.

This trial showed that the FeNO group had a significantly lower rate of asthma exacerbations during pregnancy $(\mathrm{p}=0.001)$ and unscheduled doctor visits due to asthma during pregnancy $(\mathrm{p}=0.002)$ [38]. However the ACQ scores (symptom-free days) and the AQLQ-M scores of the two groups were not significantly different at the end of the study [38]. The mean daily ICS dose was lower in the FeNO group throughout the study. A higher median birth weight as well as a reduction in preterm deliveries and neonatal hospitalizations was also found in this group [38].

\section{Discussion}

This systematic review evaluated the effectiveness of non-pharmacological healthcare interventions for improving asthma management in pregnant women. The three studies included in the review assessed education, PMR and a FeNO-based algorithm, which were found to have some positive effects on asthma management in pregnancy. Firm conclusions however, cannot be drawn due to the limited number of reported studies, clinical heterogeneity of the interventions, variations in outcome measures and limitations in study designs.

Patient education is the cornerstone of asthma management during pregnancy as it promotes adherence and in turn, improves asthma control [16]. Gibson et al. [39] identified four components of an effective asthma education program: (1) information about asthma and its management, (2) self-monitoring of either symptoms or peak expiratory flow rate, (3) regular medical review for assessing asthma control, severity and medications, and (4) a written action plan to guide patient self-management of asthma exacerbations. Pregnant women with asthma should have a basic understanding of self-monitoring, how to use asthma medications correctly, how to manage worsening asthma and the importance of continued adherence to asthma management plans [16]. Asthma education programs and self-management skills have been proven to be effective in improving health outcomes in adults with asthma [18]. Both the studies of Murphy et al. [36] and Powell et al. [38] provided education to pregnant women on skills and knowledge to manage their asthma, leading to improvement in adherence to medication regimens and asthma action plans.

The 30-min PMR sessions three times a week showed a greater improvement in lung function compared to sham training [37]. A systematic review by Huntley et al. [40] concluded that muscular relaxation may improve lung function. However, there was no evidence for effectiveness on asthma symptoms in pregnant women with asthma. The effects of educational interventions and PMR on asthma at different stages of gestation remain unknown.

The outcomes measured varied among the three studies. Lung function (e.g. $\mathrm{FEV}_{1}$, PEF) was measured as an outcome in all of the studies included. All three studies showed some improvement in $\mathrm{FEV}_{1}$, although only one study demonstrated a significant improvement in $\mathrm{FEV}_{1}$ as a result of the intervention [37]. During pregnancy, static lung function remains the same except for a reduction in functional residual capacity (FRC), expiratory reserve volume (ERV) and residual volume (RV) [41]. As the uterus enlarges, FRC decreases by $10 \%$ to $25 \%$ of the previous value due to a $35 \%$ to $40 \%$ decrease in chest wall compliance [42]. Normal pregnancy may have no significant effect on airway function. However in pregnant women with asthma, peak flow rate, $\mathrm{FEV}_{1}$ and FVC may decrease particularly during acute exacerbations [43]. The study by Schatz et al. [44] observed that it is important to measure $\mathrm{FEV}_{1}$ regularly during pregnancy, both as a prognostic factor for perinatal outcomes and as a measure of asthma control. Monitoring lung function using spirometry is recommended in the initial assessment of all pregnant women with asthma and periodically as needed [45], although lung function is typically impaired only in severe asthma and during acute exacerbations. Further studies are needed to confirm the efficacy of healthcare interventions in pregnant women with asthma over different trimesters, as pulmonary function changes throughout pregnancy in asthmatic women $[6,43,46]$.

Powell et al. [38] reported a significant reduction in the rate of unscheduled doctor visits for asthma and oral corticosteroid use in patients receiving FeNO-guided management. Reduced asthma exacerbations leading to improvements in both maternal and neonatal outcomes were also reported [38]. The application of FeNO as a biomarker of airway inflammation for the adjustments of ICS treatment to guide asthma management has been widely studied, however the results are as yet inconclusive. Several studies have shown that FeNO-guided asthma management is no more effective in reducing asthma exacerbations than current asthma guidelines and conventional pulmonary tests using spirometry [47-50]. Daily FeNO monitoring has been shown to be of no added value compared to daily symptom monitoring. Moreover, FeNO measurements are not routinely available in most clinical settings [11]. 
The American Thoracic Society [51] recommends FeNO for monitoring airway inflammation in patients with asthma. However, there is insufficient evidence to support more widespread use. Various confounders, including sex, age, height, measurement technique, exhalation flow rate, smoking, anti-inflammatory medications and even what the patient ate for breakfast, may affect FeNO results [51]. A cross-sectional study by Tamasi et al. [32] showed that in pregnant women with asthma, FeNO levels are elevated compared to healthy pregnant women and they correlate with the level of asthma control. Further studies comparing FeNO-guided asthma management with simple implementation of asthma guidelines in conjunction with conventional lung function monitoring, especially in pregnant women, are required to confirm any advantage of FeNO monitoring over traditional monitoring/ self-management.

\section{Strengths and weaknesses of this review}

This is the first systematic review of the effectiveness of non-pharmacological healthcare interventions for managing asthma and improving health outcomes in pregnant women with asthma. Unpublished studies were not included in this review. A meta-analysis was not possible because of the clinical heterogeneity of the data and study designs.

\section{Practice and research implications}

A clinical algorithm for asthma management based on objective measures and asthma symptoms could potentially reduce asthma exacerbations during pregnancy. The goals of asthma management in pregnant women are the same as in non-pregnant patients, which are to control asthma symptoms, maximize lung function, minimize medication side effects and prevent asthma exacerbations. These goals need to be considered when designing interventions, in addition to pharmacological treatment, to improve health outcomes in pregnant women with asthma. The cost-effectiveness of interventions and satisfaction of patients and health professionals also need to be assessed before implementation of such interventions in clinical practice. Further evidence is needed from well-designed prospective controlled studies in pregnant women with asthma investigating the effectiveness of interventions that incorporate patient education, patient self-management and periodic followup with health professionals.

\section{Conclusions}

Our review suggests that non-pharmacological healthcare interventions including education, self-management, progressive muscle relaxation and periodic follow-up may optimize asthma management in pregnancy. Interventions that enable pregnant women to be monitored regularly using objective measures of lung function or asthma symptoms appear to be more effective in improving health outcomes during pregnancy.

\section{Abbreviations}

ACQ: Asthma control questionnaire; AQLQ-M; AQLQ-M: Asthma quality of life questionnaire - marks; FeNO: Fraction of exhaled nitric oxide; FEV $_{1}$ : Forced expiratory volume in 1 second; FVC: Forced vital capacity; ICS: Inhaled corticosteroid; PEF: Peak expiratory flow rate; PMR: Progressive muscle relaxation; SF- 12: Short form-12; SF-36: Short form-36.

\section{Competing interests}

JG and MA hold an investigator-initiated grant from Pfizer for unrelated research. The other authors declare that they have no conflicts of interest.

\section{Authors' contributions}

EZ searched the literature and selected the studies. She also extracted and assessed the relevant data, working with JG and KS. EZ drafted the manuscript and developed it with input from all the authors. All authors approved the final manuscript.

\section{Acknowledgements}

We would like to acknowledge the Directorate General Higher Education of Indonesia and Airlangga University Indonesia for supporting EZ with a PhD scholarship.

\section{Author details}

${ }^{1}$ Centre for Medicine Use and Safety, Monash University, Parkville, VIC, Australia. ${ }^{2}$ Department of Epidemiology and Preventive Medicine, Monash University, Melbourne, VIC, Australia. ${ }^{3}$ Department of Allergy, Immunology and Respiratory Medicine, The Alfred Hospital, Melbourne, VIC, Australia.

Received: 12 December 2013 Accepted: 7 March 2014

Published: 19 March 2014

\section{References}

1. Bousquet J, Khaltaev N: Global surveillance, prevention and control of chronic respiratory diease: a comprehensive approach 2007. In Switzerland: World Health Organization; 2007.

2. GINA Report: Global strategy for asthma management and prevention. In 2010. From the Global Strategy for Asthma (GINA) http://www. ginasthma.org.

3. Kwon HL, Triche EW, Belanger K, Bracken MB: The epidemiology of asthma during pregnancy: prevalence, diagnosis, and symptoms. Immunol Allergy Clin North Am 2006, 26:29-62.

4. Kwon H, Belanger K, Bracken M: Asthma prevalence among pregnant and childbearing-aged women in the United States: estimates from national health surveys. Ann Epidemiol 2003, 13:317-324.

5. Sawicki E, Stewart K, Wong S, Leung L, Paul E, George J: Medication use for chronic health conditions by pregnant women attending an Australian maternity hospital. Aust N Z J Obstet Gynaecol 2011, 51:333-338.

6. Schatz M, Harden K, Forsythe A, Chilingar L, Hoffman C, Sperling W, Zeiger RS: The course of asthma during pregnancy, post partum, and with successive pregnancies: a prospective analysis. J Allergy Clin Immunol 1988, 81:509-517.

7. Sawicki E, Stewart K, Wong S, Paul E, Leung L, George J: Management of asthma by pregnant women attending an Australian maternity hospital. Aust N Z J Obstet Gynaecol 2012, 52:183-188.

8. Murphy VE, Wang G, Namazy JA, Powell H, Gibson PG, Chambers C, Schatz $M$ : The risk of congenital malformations, perinatal mortality and neonatal hospitalisation among pregnant women with asthma: a systematic review and meta-analysis. BJOG 2013, 120:812-822.

9. Namazy JA, Murphy VE, Powell H, Gibson PG, Chambers C, Schatz M: Effects of asthma severity, exacerbations and oral corticosteroids on perinatal outcomes. Eur Respir J 2013, 41:1082-1090.

10. Wen SW, Demissie K, Liu S: Adverse outcomes in pregnancies of asthmatic women: results from a Canadian population. Ann Epidemiol 2001, 11:7-12.

11. BTS 2007, British Thoracic Society, Scottish Intercollegiate Guideline Network: British guideline on the management of asthma 2007. 
[http://www.sign.ac.uk/guidelines]. Asthma in pregnancy. Thorax 2008, 63(Suppl 4):iv1-iv121.

12. National Heart Lung, and Blood Institute: Managing special situationspregnancy. In National Asthma Education and Prevention Program (NAEPP) Expert Panel Report 3: Guidelines for the Diagnosis and Management of Asthma. Rockville, MD: US Department of Health and Human Services NIH Publication; 2007:365-366.

13. American College of Obstetrician \& Gnyecologists (ACOG) and the American College of Allergy (ACAAI): Position statement: the use of newer asthma and allergy medications during pregnancy. Ann Allergy Asthma Immunol 2000, 84:475-480.

14. National Asthma Council of Australia: Pregnancy and asthma. In Asthma Management Handbook. Melbourne: National Asthma Council Ltd; 2006:101-103.

15. Bateman ED, Hurd SS, Barnes PJ, Bousquet J, Drazen JM, FitzGerald M, Gibson P, Ohta K, O'Byrne P, Pedersen SE, Pizzichini E, Sullivan SD, Wenzel SE, Zar HJ: Global strategy for asthma management and prevention: GINA executive summary. Eur Respir J 2008, 31:143-178.

16. Busse WW: NAEPP expert panel report: managing asthma during pregnancy: recommendations for pharmacologic treatment-2004 update. J Allergy Clin Immunol 2005, 115:34-46.

17. Guy ES, Kirumaki A, Hanania NA: Acute asthma in pregnancy. Crit Care Clin 2004, 20:731-745

18. Gibson PG, Powell H, Coughlan J, Wilson AJ, Abramson M, Haywood P, Bauman A, Hensley MJ, Walters EH: Self-management education and regular practitioner review for adults with asthma. Cochrane Database Syst Rev 2003:CD001117.

19. Maselli DJ, Adams SG, Peters JI, Levine SM: Management of asthma during pregnancy. Ther Adv Respir Dis 2013, 7:87-100.

20. Ostrom NK: Women with asthma: a review of potential variables and preferred medical management. Ann Allergy Asthma Immunol 2006, 96:655-665.

21. Schatz M, Leibman C: Inhaled corticosteroid use and outcomes in pregnancy. Ann Allergy Asthma Immunol 2005, 95:234-238.

22. Dombrowski MP, Schatz M, Wise R, Thom EA, Landon M, Mabie W, Newman RB, McNellis D, Hauth JC, Lindheimer M, Lindheimer M, Caritis SN, Leveno KJ, Meis P, Miodovnik M, Wapner RJ, Varner MW, O'Sullivan MJ, Conway DL: Randomized trial of inhaled beclomethasone dipropionate versus theophylline for moderate asthma during pregnancy. Am J Obstet Gynecol 2004, 190:737-744.

23. Lim AS, Stewart K, Abramson MJ, George J: Management of asthma in pregnant women by general practitioners: a cross sectional survey. BMC Fam Pract 2011, 12:1-7.

24. Lim AS, Stewart K, Abramson MJ, Ryan K, George J: Asthma during pregnancy: the experiences, concerns and views of pregnant women with asthma. J Asthma 2012, 49:474-479.

25. Juniper EF, O'Byrne PM, Guyatt GH, Ferrie PJ, King DR: Development and validation of a questionnaire to measure asthma control. Eur Respir J 1999, 14:902-907.

26. Marks GB, Dunn SM, Woolcock AJ: A scale for the measurement of quality of life in adults with asthma. J Clin Epidemiol 1992, 45:461-472.

27. Higgins JPT, Green S: Cochrane handbook for systematic reviews of interventions version 5.1.0 [updated March 2011]. In The Cochrane Collaboration; 2011. http://www.cochrane-handbook.org/.

28. Lozano P: Interventions to improve the management of asthma in primary care settings (Protocol). Cochrane Database Syst Rev 2003, CD004537. doi:10.1002/14651858.CD004537.

29. Moher D, Liberati A, Tetzlaff J, Altman DG: Preferred reporting items for systematic reviews and meta-analyses: the PRISMA statement. BMJ 2009, 339:b2535.

30. Ziegler A: Asthma management during pregnancy. J Ark Med Soc 2005 102:20-24.

31. Charlton RA, Hutchison A, Davis KJ, de Vries CS: Asthma management in pregnancy. PLoS One 2013, 8:e60247.

32. Tamasi L, Bohacs A, Bikov A, Andorka C, Rigo J Jr, Losonczy G, Horvath I: Exhaled nitric oxide in pregnant healthy and asthmatic women. J Asthma 2009, 46:786-791.

33. Schatz M, Dombrowski MP, Wise R, Lai $Y$, Landon M, Newman RB, Rouse DJ, Miodovnik M, O'Sullivan MJ, Caritis SN, Leveno KJ, Wapner RJ, Conway DL: The relationship of asthma-specific quality of life during pregnancy to subsequent asthma and perinatal morbidity. J Asthma 2010, 47:46-50.
34. Powell H, McCaffery K, Murphy VE, Hensley MJ, Clifton VL, Giles W, Gibson PG: Psychosocial outcomes are related to asthma control and quality of life in pregnant women with asthma. J Asthma 2011, 48:1032-1040.

35. Powell H, McCaffery K, Murphy VE, Hensley MJ, Clifton VL, Giles W, Gibson PG: Psychosocial variables are related to future exacerbation risk and perinatal outcomes in pregnant women with asthma. J Asthma 2013, 50:383-389.

36. Murphy VE, Gibson PG, Talbot PI, Kessell CG, Clifton VL: Asthma selfmanagement skills and the use of asthma education during pregnancy. Eur Respir J 2005, 26:435-441.

37. Nickel C, Lahmann C, Muehlbacher M, Pedrosa Gil F, Kaplan P, Buschmann W, Tritt K, Kettler C, Bachler E, Egger C, Anvar J, Fartacek R, Loew T, Rother W, Nickel M: Pregnant women with bronchial asthma benefit from progressive muscle relaxation: a randomized, prospective, controlled trial. Psychother Psychosom 2006, 75:237-243.

38. Powell H, Murphy VE, Taylor DR, Hensley MJ, McCaffery K, Giles W, Clifton VL, Gibson PG: Management of asthma in pregnancy guided by measurement of fraction of exhaled nitric oxide: a double-blind, randomised controlled trial. Lancet 2011, 378:983-990.

39. Gibson PG, Ram FSF, Powell H: Asthma education. Respir Med 2003, 97:1036-1044.

40. Huntley A, White AR, Ernst E: Relaxation therapies for asthma: a systematic review. Thorax 2002, 57:127-131.

41. Hegewald MJ, Crapo RO: Respiratory physiology in pregnancy. Clin Chest Med 2011, 32:1-13. vii.

42. Wise RA, Polito AJ: Respiratory physiologic changes in pregnancy. Immunol Allergy Clin North Am 2000, 20:663-672.

43. Bealert S, Greenberger PA: Chapter 16: asthma in pregnancy. Allergy Asthma Proc 2012, 33:55-57.

44. Schatz M, Dombrowski MP, Wise R, Momirova V, Landon M, Mabie W, Newman RB, Rouse DJ, Lindheimer M, Miodovnik M, Caritis SN, Leveno KJ, Meis P, Wapner RJ, Paul RH, O'Sullivan MJ, Varner MW, Thurnau GR, Conway $\mathrm{DL}$ : Spirometry is related to perinatal outcomes in pregnant women with asthma. Am J Obstet Gynecol 2006, 194:120-126.

45. NAEPP expert panel report: Report of The Working Group on Asthma and Pregnancy: Management of asthma during pregnancy. NIH Publication No.93-3279A. Bethesda (MD): US Department of Health and Human Services; national Institutes of Health; National Heart, Lung and Blood Institute, Maryland; 1993. http://www.nhlbi.nih.gov/health/prof/lung/ asthma/astpreg.txt

46. White RJ, Coutts II, Gibbs CJ, Maclntyre C: A prospective study of asthma during pregnancy and the puerperium. Respir Med 1989, 83:103-106.

47. Gelb AF, Flynn Taylor C, Shinar CM, Gutierrez C, Zamel N: Role of spirometry and exhaled nitric oxide to predict exacerbations in treated asthmatics. Chest 2006, 129:1492-1499.

48. Shaw DE, Berry MA, Thomas M, Green RH, Brightling CE, Wardlaw AJ, Pavord ID: The use of exhaled nitric oxide to guide asthma management: a randomized controlled trial. Am J Respir Crit Care Med 2007, 176:231-237.

49. Szefler SJ, Mitchell H, Sorkness CA, Gergen PJ, O'Connor GT, Morgan WJ, Kattan M, Pongracic JA, Teach SJ, Bloomberg GR, Eggleston PA, Gruchalla RS, Kercsmar CM, Liu AH, Wildfire JJ, Curry MD, Busse WW: Management of asthma based on exhaled nitric oxide in addition to guideline-based treatment for inner-city adolescents and young adults: a randomised controlled trial. Lancet 2008, 372:1065-1072

50. Smith AD, Cowan JO, Brassett KP, Herbison GP, Taylor DR: Use of exhaled nitric oxide measurements to guide treatment in chronic asthma. $N$ Engl J Med 2005, 352:2163-2173.

51. Dweik RA, Boggs PB, Erzurum SC, Irvin CG, Leigh MW, Lundberg JO, Olin AC, Plummer AL, Taylor DR: An official ATS clinical practice guideline: interpretation of exhaled nitric oxide levels (FENO) for clinical applications. Am J Respir Crit Care Med 2011, 184:602-615.

doi:10.1186/1471-2466-14-46

Cite this article as: Zairina et al.: The effectiveness of non-pharmacological healthcare interventions for asthma management during pregnancy: a systematic review. BMC Pulmonary Medicine 2014 14:46. 